Document downloaded from:

http://hdl.handle.net/10251/63338

This paper must be cited as:

Ortiz Sánchez, MC.; Blasco, J.; Balasch Parisi, S.; Torregrosa Mira, A. (2011). Shock absorbing reception surfaces for collecting fruit during the mechanical harvesting of citrus. Biosystems Engineering. 110(1):2-9. doi:10.1016/j.biosystemseng.2011.05.006.

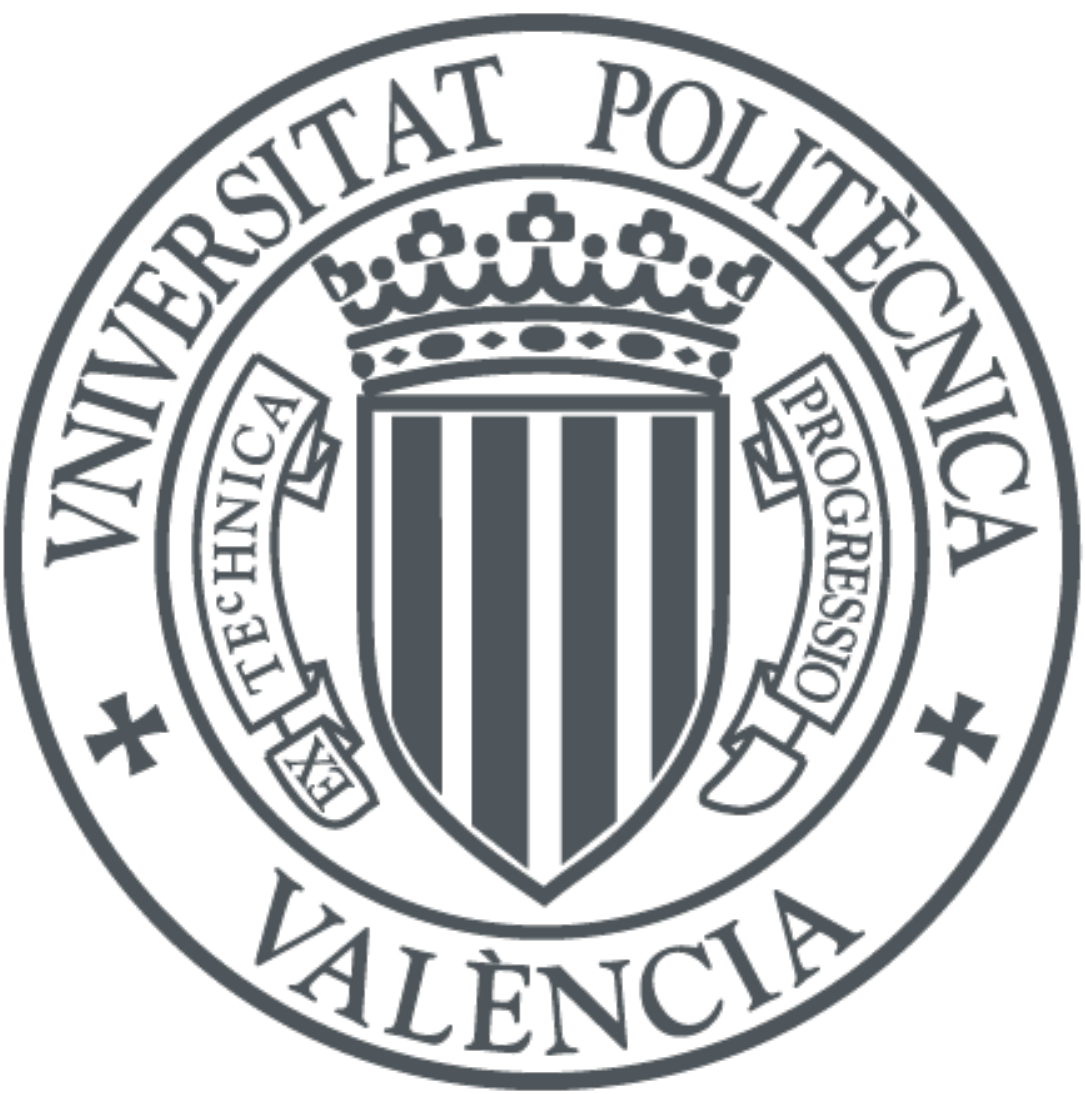

The final publication is available at

http://dx.doi.org/10.1016/j.biosystemseng.2011.05.006

Copyright Elsevier

Additional Information 


\title{
Shock absorbing surfaces for collecting fruit citrus during the mechanical harvesting of citrus
}

\author{
C. Ortiz ${ }^{1),}$, J. Blasco ${ }^{2)}$, S. Balasch ${ }^{3)}$, A. Torregrosa ${ }^{1)}$ \\ 1) Dpto. Ingeniería Rural y Agroalimentaria, Universidad Politécnica de Valencia. Camino de Vera s/n, \\ 46022 Valencia cortiz@dmta.upv.es \\ 2) Instituto Valenciano de Investigaciones Agrarias \\ 3) Dpto. de Estadística e Investigación Operativa Aplicadas y Calidad. Universidad Politécnica \\ Valencia
}

\begin{abstract}
Damage to fresh citrus caused by impact of fruits onto collecting surfaces has restricted the adoption of mechanical harvesting. Two different experiments were developed in this research work: citrus free dropping experiment and shock absorbing capacity experiment. In the citrus fruit free dropping experiment, mandarin, orange and lemon fruit damage was studied. Three reception surfaces were studied (concrete floor, elevated canvases provided with a frame and wheels and concrete floor covered with shock absorber canvases). Three dropping heights were studied. In the shock absorbing capacity experiment, an electronic sphere and a triaxial accelerometer were used to measure the shocking capacity of seven reception surfaces (ground, ground covered with shock absorber canvases, ground covered with weeds, ground covered with "mulch" and elevated canvases provided with a frame and wheels). Elevated canvases had the higher shock absorbing capacity compared to the other surfaces $\left(260 \mathrm{~m} \mathrm{~s}^{-2}\right.$ maximum acceleration compared with $1753 \mathrm{~m} \mathrm{~s}^{-2}$ to $2772 \mathrm{~m} \mathrm{~s}^{-2}$ ). Weeds, mulch and shock absorbing canvases showed significantly higher shock absorbing capacity than the field ground. Besides, shock absorber canvases covering concrete floor reduce impact and fruit damage $\left(1866 \mathrm{~m} \mathrm{~s}^{-2}\right.$ maximum acceleration compared to $2477 \mathrm{~m} \mathrm{~s}^{-2}$ ). Citrus damage susceptibility during harvest depend on the variety. Elevated canvases and shock absorber canvases could be used as reception systems in fresh market citrus mechanical harvesting.
\end{abstract}

Keywords: mechanical harvesting, citrus, fruit damage, electronic sphere, reception surface, logistic regression

\begin{tabular}{|l|l|}
\hline Nomenclature & \\
B & Blank sample \\
C & Concrete floor \\
CC & Concrete floor covered with the shock absorbing canvases \\
W & Ground covered with weeds \\
G & Ground \\
GC & Ground covered with the shock absorbing canvases \\
$\mathrm{Mu}$ & Ground covered with "mulch" \\
E & Elevated canvases with frame and wheels \\
\hline
\end{tabular}

\section{Introduction}

The number of fresh market crops currently mechanically harvested is small. Mechanical harvester-based production systems are evolving to reduce field losses and fruit damage (Glancey, 2005). In Spain, all citrus harvesting is performed by hand (Torregrosa, Gil, Ortiz, Ortí, 2009). It accounts for half the total crop production costs. Citrus farmer incomes have decreased by more than $20 \%$ in the last 5 years. A reduction of the high harvesting costs could help to maintain the crop profitability. Mechanical harvesting could be an alternative to traditional harvesting in order to reduce harvesting costs. However, fresh market citrus damage during reception restricts mechanical harvesting. Thus is necessary to assess fruit damage during harvesting.

Citrus fruit damage during harvest and postharvest handling could be due to impacts, compressions or frictions. Citrus fruit damages are difficult to measure in an external quality assessment. However, friction damages are easier to detect due to the olecellosis or oil spotting (Fornes, Moltó, Juste, 1994). 
Juste, Gracia, Molto, Ibañez and Castillo (1988) tested citrus fruit physical properties for fresh fruit mechanical harvesting. Puncture tests were carried out during four harvesting times along the growth season. It is important to determine the safe handling limits for citrus fruit during harvesting. Menesatti, Paglia, Solaini, Niciarelli and D'Andrea (2005) measured firmness and elasticity of different citrus fruits. Mandarins presented less firmness and elasticity than oranges and lemons. Significant differences were found between different varieties. It is necessary to provide growers with the information to choose fresh market citrus varieties acceptable to consumers and resistant to mechanical handling. Flood, Burks, Texeira (2006) studied the physical properties of oranges using puncture and burst tests, a model was developed that relates punch diameter to puncture force. Recommendations were made in order to design a grasping robotic citrus harvester end-effector.

Pang, Studman, Banks and Baas (1996) proposed a method for rapid assessment of bruise damage in order to assess in laboratory the susceptibility of apples to bruising with field experience during handling, The method involves dropping fruit from a geometrically increasing series of heights onto a flat steel surface using a pendulum, and counting the number of bruises observed with skin impact. The resulting number is termed the bruise factor, to distinguish it from other measurements of bruising. The bruise factor test requires a sample of 20 fruit.

Timm and Guyer (1998) developed drop tests to evaluate cherry firmness sensitivity and identified cushion materials that could reduce firmness loss during mechanical harvesting. They tested four different cushion materials and compared them to a hard surface. Firmness loss averaged $28 \%$ for a $0.9 \mathrm{~m}$ drop onto a hard surface compared to 6 to $10 \%$ for the four cushion materials.

Lu and Wang (2007) compared the conventional testing methods and free-fall dropping tests. Free-fall dropping tests with a series of drop heights were conducted on fresh Gala apples. The dropping impact acceleration, velocity, and deformation change during contact at various drop heights were obtained. The relationship between bruising deformation and theoretical deformation of the samples was determined. The results showed there were obvious differences between dropping bruise boundary of apples and conventional damage boundary of products.

Scherrer Montero et al. (2009) evaluated mechanical damage of tangerines by visual and chemical quality assessment. Harvested tangerines were submitted to different degrees of impact by letting the fruit fall from $0.4 \mathrm{~m}, 0.6 \mathrm{~m}, 0.8 \mathrm{~m}$ and $1.0 \mathrm{~m}$ heights. Each fruit was dropped twice from the same height onto a rigid ceramic surface. There were three replicates, with six fruits for each experimental unit for each cultivar. The main modifications produced by impact on the fruit were losses of citric acid and soluble solids.

In Valencia (Spain), due to the citrus fresh market and the orchard conditions, canopy shakers and citrus fruit picking-up machines (Bora \& Ehsani, 2009) could not be used for mechanical harvesting. Trunk shakers have been studied and adapted for citrus mechanical harvesting. However, fruit reception is not already achieved. In peaches, elevated canvases provided with a frame and wheels have been developed to catch the fruit (Torregrosa, Martín, Ortiz, Chaparro, 2008). The experiments were carried out on a crop of Caterina peaches. Three catching systems were tested: A) a pair of canvases, B) a catching trailer with extendable flat planes, and C) a pair of canvases with direct discharge to boxes. Less than $2.4 \%$ of the fruits were severely injured. System $\mathrm{C}$ was also tested to harvest fresh market Tardivel peaches, in this case $13 \%$ of the fruits were damaged to some extent (severe and slight) and this was not acceptable for the producers. Fruit damage during harvesting is due to the branch impacts when falling and to the impact on the reception surface

In fruit harvest and postharvest handling systems, cushioning and velocity control devices are used to avoid bruising (Amrstrong, Brown, Timm, 1995). A cushioning material must provide effective energy absorption and dissipation and not create the critical stress/strain level in the produce tissue that will initiate bruising.

In agricultural engineering, electronic spheres (or electronic fruits) are commonly used to evaluate fruits damage during mechanical handling (harvest and postharvest). 
Van Canney, Tijkens, Ramon, Verschoe and Sonck (2003) studied the measuring characteristics of a PTR 200 electronic sphere when impacting five materials, frequently used on commercial potato harvesters. Hard materials with little energy absorption and soft materials with strong cushioning effects were chosen. Different heights from $0.1 \mathrm{~m}$ to $1 \mathrm{~m}$ were studied depending on the cushioning effect of the material.

Hernández (2000) tried to compare citrus fruit damage and electronic sphere data. An impact electronic sphere IS100 and a pressure electronic sphere PMS60 were used. Clauselina mandarin and Navelina orange damage were tested letting the fruit fall from different heights. Mandarins were dropped from 0.08 $\mathrm{m}$ to $1.48 \mathrm{~m}$ over a steel surface, fruits dropped from less than $0.7 \mathrm{~m}$ did not presented olleocelosis damage. Oranges were dropped from $0.10 \mathrm{~m}$ to $0.75 \mathrm{~m}$ over a ceramic surface.

Garcia-Ramos, Ruiz-Altisent and Ortiz-Cañavate (2004) studied different types of orange packing systems (packing table, box filler and net filler) using an instrumented sphere IS 100 in four orange packing lines in the Valencia region (Spain). Ortiz et al. (2007) studied the damage susceptibility of two different surfaces used for fruit harvesting. An electronic sphere was used to compare the shock absorbing capacity of different materials used in two different systems: a pair of canvases and a catching trailer with extendable flat planes. Fisher, Ferreira, Spósito and Amorim (2009) characterized postharvest injuries in Valencia oranges and Murcott tangors after different processing stages in a packinghouse and compared them to the acceleration registered with an instrumented sphere. Impacts in the processing line were caused mainly by drops on hard surfaces.

\section{Objective}

To assess citrus fruit damage during mechanical harvesting according to the reception surface and to determine the shock absorbing capacity of different reception surfaces for citrus mechanical harvesting.

To compare the usefulness of an electronic sphere PTR200 and a ceramic triaxial accelerometer to assess the shock absorbing capacity of different reception surfaces for citrus mechanical harvesting.

\section{Materials y methods}

Two different experiments were carried out:

(1) Citrus free dropping tests

(2) Shock absorbing capacity tests

\subsection{Citrus free dropping tests}

Mandarin (Orogrande and Clemenules), orange (Navel Lane Late) and lemon (Fino) fruit damage was studied during harvesting reception. Citrus were manually detached two hours before the dropping test was carried out. Mandarin and orange varieties were collected when the commercial harvesting operations were carried out in the orchards. Two sets of Fino lemons were tested: green unripe set and yellow ripe set. Two factors were studied: reception surface and drop height. Citrus were dropped over three reception surfaces: concrete floor $(\mathrm{C})$, elevated canvases provided with a frame and wheels $(\mathrm{E})$ and concrete floor covered with shock absorber canvases (CC).

The elevated canvases are rectangular shape canvases ( $3 \mathrm{~m}$ x $3 \mathrm{~m})$, made of flexible waterproof material. They are attached with elastic ropes to a tubular aluminium structure and provided with four wheels to ensure easy movement and to be adjustable to different heights (from 0.25 $\mathrm{m}$ to $0.75 \mathrm{~m})$. 
Fruits were dropped from three different drop heights: $0.5 \mathrm{~m}, 1 \mathrm{~m}$ and $2 \mathrm{~m}$ (in Valencia, citrus trees have a maximum height of 2.5-3 m). Fruits were stored under room conditions $\left(20^{\circ} \mathrm{C}\right.$ and $\left.60 \% \mathrm{RH}\right)$.

Slightly damaged fruit percentage and rotten fruit percentage were evaluated according to the local market standards, after two weeks storage.

Thirty fruits were studied in each sample. One sample from each variety was used as blank sample. Thirty more fruits from each variety were used to measure weight, soluble solid content and acidity.

\subsection{Shock absorbing capacity tests}

An impact electronic sphere or electronic sphere PTR 200 (a digital electronic potato for impact detection, $168 \mathrm{~g}$, three axis, percentage scale, www.martinlishman.com) and a ceramic triaxial accelerometer (Kistler type 8763A500; range $\pm 500 \mathrm{G}$; sensitivity $10 \mathrm{mV} / \mathrm{G}$; weight $3.3 \mathrm{~g}$; mini cube design $0.01 \mathrm{~m}$ length; www.kistler.com) were used to study the shock absorbing capacity of different reception surfaces.

Figure 1. The triaxial accelerometer and the electronic sphere.

The triaxial accelerometer was located on the top part of the electronic sphere and was stuck to the electronic sphere wrapped with tape (Figure 1). The electronic sphere was dropped fifteen times for 0.5 $\mathrm{m}, 1 \mathrm{~m}$ and $2 \mathrm{~m}$ over the surfaces: concrete floor $(\mathrm{C})$; concrete floor covered with shock absorber canvases, plastic canvas with cushioning bubble material (CC); ground, natural field soil surface (G); ground covered with shock absorber canvases (GC); ground covered with weeds (W); ground covered with "mulch" $(\mathrm{Mu})$ and elevated canvases provided with frame and wheels, rectangular aluminium tube structure ( 4 x 3 m, 0.04 m diameter), with plastic material canvases tightened with elastic ropes (E).

It was not possible to register data from $1 \mathrm{~m}$ and to $2 \mathrm{~m}$ height dropping over $\mathrm{C}$ and $\mathrm{CC}$ due to the damage that could be caused to the electronic sphere devise. The electronic sphere is not able to register more than $100 \%$ of its range.

The electronic sphere impact percentage and the accelerometer maximum acceleration were measured.

In the citrus free dropping tests, a logistic regression analysis (Kleinbaum and Klein, 2002) was used to assess fruit damage $(0=$ not damaged, $1=$ damaged $)$ according to the dropping height and the reception surface.

In the shock absorbing capacity tests, one-way analysis of variance and two-way analysis of variance were developed to study the effect of the dropping height and the reception surface in the shocking absorbing capacity measured with the electronic sphere and the accelerometer. Duncan multiple range tests (Jobson, 1991) were carried out to study the different effects of the surfaces.

Statistical analyses were performed using a commercially available statistics package (Statgraphics Plus, version 5.1., STSC Inc., Rockville, MD, USA). 


\section{Results and discussion}

\subsection{Fruit dropping tests}

The tests have shown that citrus damage susceptibility depend on variety and ripeness stage (Table 1), as found by Menesatti et al. (2005), therefore we are going to analyse the results based on variety.

Table 1. Rotten fruit percentage according to variety, dropping height and reception surface.

\begin{tabular}{|c|c|c|c|c|c|c|c|c|c|c|c|c|}
\hline & \multicolumn{4}{|c|}{$0.5 \mathrm{~m}$} & \multicolumn{4}{|c|}{$1 \mathrm{~m}$} & \multicolumn{4}{|c|}{$2 \mathrm{~m}$} \\
\hline & B & $\mathbf{E}$ & $\mathbf{C C}$ & $\mathbf{C}$ & B & $\mathbf{E}$ & $\mathbf{C C}$ & $\mathbf{C}$ & B & $\mathbf{E}$ & $\mathrm{CC}$ & C \\
\hline Orogrande & 0 & 0 & 0 & 0 & 0 & 0 & 0 & 0 & 0 & 0 & 3 & 13 \\
\hline Clemenules & 0 & 0 & 0 & 0 & 0 & 0 & 0 & 0 & 0 & 0 & 0 & 7 \\
\hline Navel Lane Late & 0 & 0 & 4 & 8 & 0 & 0 & 4 & 8 & 0 & 4 & 60 & 75 \\
\hline Unripe Fino* & 0 & 0 & 0 & 0 & 0 & 0 & 0 & 0 & 0 & 0 & 0 & 0 \\
\hline Ripe Fino* & 0 & 0 & 0 & 0 & 0 & 0 & 0 & 0 & 0 & 0 & 3 & 7 \\
\hline
\end{tabular}

*According to the harvest date

Mandarin Orogrande dropped from a height of $0.5 \mathrm{~m}$ and $1 \mathrm{~m}$ over the shock absorber canvases placed on the concrete floor and directly over the concrete floor did not present any damage after two weeks storage. The ones dropped from $2 \mathrm{~m}$ over $\mathrm{CC}$ had $17 \%$ of slightly damaged fruits and $3 \%$ of rotten fruits. Those samples dropped directly over the concrete floor had $30 \%$ of slightly damaged fruits and $13 \%$ of rotten fruits.

Mandarins Clemenules dropped from a height of $1 \mathrm{~m}$ presented a $23 \%$ of slightly damaged fruits and those dropped from a height of $2 \mathrm{~m}$ over the concrete floor showed considerable damage (7 \% of rotten fruits).

Navel Lane Late was the variety most susceptible to damage among the ones studied. Most of the fruits were broken when impacting the surface and its elevated damage susceptibility was related to its overripe ripeness stage according to the harvesting date.

Navel Lane Late oranges dropped over the concrete floor (C) and over this covered with shock absorber canvases (CC) presented damages for all the dropping heights. In the case of $2 \mathrm{~m}$ height, the rotten percentage of the oranges dropped over $\mathrm{C}$ was $75 \%$ and over $\mathrm{CC}$ was $60 \%$. Most of the damage was produced by the broken of the fruit when impacting the surface. The logistic regression model ( $1=$ damage; $0=$ no damage) showed a significant effect of the factors height and surface, as well as, a high goodness fit between the observed and the model predicted frequencies (Table 2).

As it was expected, height has a high effect on damage percentage (estimated coefficient= 2.9). Blank sample was the surface most different to concrete floor (the reference surface), with less effect on fruit damage (estimated coefficient $=-17.4$ ), followed by the elevated canvases (estimated coefficient $=-4.3$ ), and the concrete floor covered (estimated coefficient $=-0.7$ ). The model also evidences significant differences in the damage produced with the three surfaces. 
Table 2. Logistic regression adjusted model for Navel Lane Late oranges.

\begin{tabular}{|c|c|c|c|}
\hline & \multicolumn{2}{|c|}{ Estimated coefficient } & Likelihood ratio test (significance) \\
\hline & Constant & -4.7 & \\
\hline & Height & 2.9 & Chi-square $=66.1, \mathrm{df}=1, \mathrm{p}$-value $<0.01$ \\
\hline & $\mathrm{CC}$ & -0.7 & \\
\hline Surface & $\mathrm{E}$ & -4.3 & Chi-square $=68.0, \mathrm{df}=3, \mathrm{p}$-value $<0.01$ \\
\hline & B & -17.4 & \\
\hline \multicolumn{4}{|c|}{ Goodness fit: Hosmer-Lemeshow Chi-square $=2.0, \mathrm{df}=3, \mathrm{p}$-value $=0.57$} \\
\hline
\end{tabular}

Fino lemons harvested in the green stage did not present any damage, even those dropped from $2 \mathrm{~m}$ directly over the concrete floor. However, ripe lemons dropped from $2 \mathrm{~m}$ height presented a $3 \%$ of rotten fruits over $\mathrm{CC}$ and $7 \%$ over $\mathrm{C}$.

Fruit dropped over the elevated canvases did not show any damage, with the exception of Navel Lane Late oranges dropped from $2 \mathrm{~m}$ height. The citrus caught with this reception surface showed a similar level of damage as manual harvesting (blank sample) even when they were dropped from $2 \mathrm{~m}$ height. They could be used as reception systems in fresh market citrus mechanical harvesting as the average citrus tree height is $2.5 \mathrm{~m}$

\subsection{Shock absorbing capacity tests}

Elevated canvases had the higher shock absorbing capacity (average accelerometer measurement below $500 \mathrm{~ms}^{-2}$ and average impact value under 15\%). The weeds shock absorbing capacity was higher than the "mulch" and the ground covered with canvases. The shock absorbing canvases lightly increase the shock absorbing capacity of the concrete floor measured by the accelerometer for $0.5 \mathrm{~m}$ dropping height. The ground showed a higher shock absorbing capacity than the concrete floor. The ground covered with shock absorbing canvases did not increase the shock absorbing capacity for $1 \mathrm{~m}$ and $2 \mathrm{~m}$ heights as compared with bare concrete.

The electronic sphere could not be used to measure $\mathrm{C}$ and $\mathrm{CC}$ from higher than 0.5 dropping height, because the devise could be damaged. When data from $0.5 \mathrm{~m}$ dropping height is analyzed, the factor surface has a high significant effect on the electronic sphere impact percentage (ANOVA analysis, Table 3 ). In the same way, surface has a significant effect on the accelerometer maximum acceleration (ANOVA analysis, Table 4).

Table 3. One-way analysis of variance of the surface in the electronic sphere impact percentage $(0.5 \mathrm{~m}$ height data).

\begin{tabular}{|c|c|c|c|c|c|c|}
\hline Source & $\begin{array}{c}\text { Sum of } \\
\text { Squares }\end{array}$ & df & & Mean Square & F-ratio & p-value \\
\hline Surface & 106941.0 & & 6 & 17823.5 & 49.8 & 0.000 \\
\hline Residual & 33318.0 & & 93 & 358.3 & & \\
\hline Total & 140259.0 & & 99 & & & \\
\hline
\end{tabular}

Table 4. One-way analysis of variance of the surface in the accelerometer maximum acceleration $(0.5 \mathrm{~m}$ height data).

\begin{tabular}{|c|c|c|c|c|c|c|}
\hline Source & $\begin{array}{c}\text { Sum of } \\
\text { Squares }\end{array}$ & df & & Mean Square & F-ratio & p-value \\
\hline Surface & 47318300.0 & & 6 & 7886390.0 & 27.2 & 0.000 \\
\hline Residual & 26925900.0 & & 93 & 289526.0 & & \\
\hline Total & 74244300.0 & & 99 & & & \\
\hline
\end{tabular}

In table 5 it is shown, for $0.5 \mathrm{~m}$ dropping height, the Duncan multiple range test of the electronic sphere impact and the accelerometer maximum acceleration according to the reception surface. The electronic sphere and the accelerometer showed that the elevated canvases (E) reduced significantly the impacts with respect to the other surfaces. 
Neither the accelerometer nor the electronic sphere showed significant differences between the ground covered with weeds (W), the ground covered with "mulch" (Mu) and the ground covered with shock absorber canvases (GC).

The electronic sphere was not able to discriminate between concrete floor (C) and concrete floor covered with shock absorber canvases (CC) due to the sensor saturation in the most severe impacts.

The accelerometer showed that, for $0.5 \mathrm{~m}$, the elevated canvases had significantly the lowest acceleration $\left(97 \mathrm{~m} \mathrm{~s}^{-2}\right)$, while the concrete floor had significantly the highest $\left(2477 \mathrm{~m} \mathrm{~s}^{-2}\right)$. When this very damaging surface (C) was covered with a shock absorber canvases (CC) the measured acceleration was significantly lower $\left(1866 \mathrm{~m} \mathrm{~s}^{-2}\right)$.

Table 5. Duncan multiple range test of the electronic sphere impact and the accelerometer maximum acceleration according to the reception surface for $0.5 \mathrm{~m}$ dropping height. Significant differences between the reception surfaces according to the impact measurement. " $\mathrm{X}$ " in the same column indicates no significant differences $(\mathrm{p}>0.05)$

\begin{tabular}{|c|c|c|c|c|c|c|c|}
\hline & & Mean & $\begin{array}{c}\text { Statistical } \\
\text { significance }\end{array}$ & & & Mean & $\begin{array}{c}\text { Statistical } \\
\text { significance }\end{array}$ \\
\hline \multirow{7}{*}{$\begin{array}{c}\text { Electronic } \\
\text { Sphere }(\%)\end{array}$} & $E$ & 7.9 & $X$ & \multirow{7}{*}{$\begin{array}{l}\text { Accelerometer } \\
\left(\mathrm{m} \mathrm{s}^{-2}\right)\end{array}$} & $E$ & 99.9 & $X$ \\
\hline & W & 25.4 & $\mathrm{X}$ & & W & 1200.0 & X \\
\hline & $\mathrm{Mu}$ & 33.4 & $X$ & & $\mathrm{Mu}$ & 1336.9 & XX \\
\hline & GC & 34.3 & $X$ & & GC & 1432.6 & XXX \\
\hline & G & 72.8 & X & & G & 1728.6 & XX \\
\hline & $\mathrm{CC}$ & 86.6 & $\mathrm{XX}$ & & $\mathrm{CC}$ & 1865.8 & X \\
\hline & $\mathrm{C}$ & 100.0 & $\mathrm{X}$ & & $\mathrm{C}$ & 2477.3 & X \\
\hline
\end{tabular}

The two factors (surface and height) and their interaction have a significant effect on the electronic sphere impact percentage (ANOVA analysis, Table 6). In the same way, surface and height and their interaction have a high significant effect on the accelerometer maximum acceleration (ANOVA analysis, Table 7). However, in both cases, the interaction effect was considerably lower than the effect of the factors. Therefore, Duncan multiple range tests were carried out for the qualitative factor (surface).

Table 6. Two-ways analysis of variance of surface and height (and their interaction) in the electronic sphere impact percentage.

\begin{tabular}{|c|c|c|c|c|c|}
\hline Source & $\begin{array}{c}\text { Sum of } \\
\text { Squares }\end{array}$ & df & Mean Square & F-ratio & p-value \\
\hline Surface & 4738.1 & 2 & 23690.6 & 62.4 & 0.000 \\
\hline Height & 112208.0 & 4 & 28052.0 & 73.9 & 0.000 \\
\hline Surface*Height & 17258.4 & 8 & 2157.3 & 5.7 & 0.000 \\
\hline Residuals & 73238.3 & 193 & 379.5 & & \\
\hline Total & 270487.0 & 207 & & & \\
\hline
\end{tabular}

Table 7. Two-way analysis of variance of surface and height (and their interaction) in the accelerometer maximum acceleration.

\begin{tabular}{lrrrrr}
\multicolumn{1}{c}{ Source } & \multicolumn{1}{c}{$\begin{array}{c}\text { Sum of } \\
\text { Squares }\end{array}$} & df & Mean Square & F-ratio & p-value \\
\hline Surface & 65344400.0 & 2 & 32672200.0 & 103.9 & 0.000 \\
Height & 138084000.0 & 4 & 34521100.0 & 109.8 & 0.000 \\
Surface*Height & 17034000.0 & 8 & 2129250.0 & 6.8 & 0.000 \\
Residuals & 60675100.0 & 193 & 314379.0 & & \\
Total & 316934000.0 & 207 & & & \\
\hline
\end{tabular}

In table 8 it is shown the Duncan multiple range test of the electronic sphere impact and the accelerometer maximum acceleration according to the reception surface and the dropping height, without the concrete floor and the concrete floor covered with shock absorber canvases data. 
Table 8. Duncan multiple range test of the electronic sphere impact and the accelerometer maximum acceleration according to the reception surface and the dropping height. Significant differences between the reception surfaces and the heights according to the impact measurement. " $\mathrm{X}$ " in the same column indicates no significant differences $(\mathrm{p}>0.05)$

\begin{tabular}{|c|c|c|c|c|c|c|c|c|c|}
\hline & & & Mean & $\begin{array}{c}\text { Statistical } \\
\text { significance }\end{array}$ & & & & Mean & $\begin{array}{c}\text { Statistical } \\
\text { significance }\end{array}$ \\
\hline $\begin{array}{l}\text { Electronic } \\
\text { Sphere (\%) }\end{array}$ & Surface & $\begin{array}{l}\text { E } \\
\text { W } \\
\text { Mu } \\
\text { GC } \\
\text { G }\end{array}$ & $\begin{array}{l}11.5 \\
61.1 \\
63.6 \\
67.9 \\
81.8\end{array}$ & $\begin{array}{l}\text { X } \\
\text { X } \\
\text { X } \\
\text { X } \\
\quad \text { X }\end{array}$ & $\begin{array}{l}\text { Accelerometer } \\
\left(\mathrm{m} \mathrm{s}^{-2}\right)\end{array}$ & Surface & $\begin{array}{l}\text { E } \\
\text { W } \\
\text { Mu } \\
\text { GC } \\
\text { G }\end{array}$ & $\begin{array}{r}259.7 \\
1752.9 \\
2056.6 \\
2410.4 \\
2772.4\end{array}$ & $\begin{array}{l}\text { X } \\
\text { X } \\
\quad \text { X } \\
\\
\text { X }\end{array}$ \\
\hline
\end{tabular}

The elevated canvases had significantly the lowest impact value compared to the other surfaces, measured by the electronic sphere and the accelerometer $\left(11,5 \%\right.$ and $259.7 \mathrm{~m} \mathrm{~s}^{-2}$ respectively). However, the electronic sphere was not able to discriminate between ground covered with weeds, ground covered with "mulch" and ground covered with shock absorber canvases due to the high variability of the sensor measurements. The electronic sphere discriminant ability between the surfaces is lower than the accelerometer one. These results agreed those found by Van Canney et al.(2003) about the strongly varying results due to anisotropic mechanical

properties, varying damping characteristics and geometry of the PTR 200 sensor zones. It is also necessary to mark the impossibility of using the electronic sphere in measuring the most severe impacts.

The accelerometer showed that the surfaces $\mathrm{W}, \mathrm{Mu}$ and GC have significantly lower acceleration than G. This result confirms the shocking capacity of shock absorber canvases, weeds and "mulch" when they are covering field ground. Weeds showed higher shock absorbing capacity covering the field ground than "mulch" and shock absorbing canvases. And "mulch" showed higher shock absorbing capacity than shock absorbing canvases.

Values registered with the two devises showed that the damage produced from the three dropping heights was significantly different according to the reception surface, as it is shown in the interaction plots (Figure 2).

Figure 2. Interaction plots. Average accelerometer measurement $\left(\mathrm{ms}^{-2}\right.$, above) and average electronic sphere impact (\%, below) for the reception surfaces.

Damage increase does not evolve in a similar way in the different surfaces. Ground covered with shock absorber canvases and ground covered with "mulch" showed a convex tendency compared to the linear tendency of the elevated canvases and the ground.

\section{Conclusions}

Citrus damage susceptibility during harvest depends on the variety.

Fruit damage tests evidenced that concrete floor was the most damaging surface, elevated canvases were the lowest and shock absorbing canvases could reduce fruit damaging.

Elevated canvases had significantly the highest shock absorbing capacity, and it had the lowest accelerations (260 $\mathrm{m} \mathrm{s}^{-2}$ maximum acceleration compared with $1753 \mathrm{~m} \mathrm{~s}^{-2}$ to $2772 \mathrm{~m} \mathrm{~s}^{-2}$ ). Weeds, mulch and shock absorbing canvases showed significantly higher shock absorbing capacity than the field ground.

The accelerometer showed that for $0.5 \mathrm{~m}$ height the acceleration over the concrete floor covered with canvases was significantly lower than over the concrete floor $\left(1866 \mathrm{~m} \mathrm{~s}^{-2}\right.$ maximum acceleration compared to $2477 \mathrm{~m} \mathrm{~s}^{-2}$ ).

The PTR200 electronic sphere has some limitations measuring the most severe impacts. The accelerometer has a higher discriminant ability to segregate different shocking materials and could be used to measure impacts from higher heights over hard surfaces.

Elevated canvases have a clear effect on avoiding fruit damage when dropping from $2 \mathrm{~m}$ heights. They could be used as reception systems in fresh market citrus mechanical harvesting. Weeds, mulch and shock 
absorbing canvases could reduce impact when they are covering field ground in citrus mechanical harvesting.

\section{Acknowledgements}

This study was funded by the Ministerio de Ciencia e Innovación (research project RTA2009-00118-C0202) and FEDER. The authors are most grateful to the following collaborators: María del Mar López Quevedo, Montano Pérez, Juan José Peña and Ángel Pérez.

\section{References}

Armstrong, P.R., Brown G.K., \& Timm E.J. (1995). Cushioning choices can avoid produce bruising during handling. Harvest and Postharvest Technologies for Fresh Fruits and Vegetables. American Society of Agricultural Engineers Publication, 183-90

Bora, G.C., \& Ehsani, R. (2009). Evaluation of a Self-Propelled Citrus Fruit Pick-Up Machine. Applied Engineering in Agricultura, 25(6), 863-868.

Fisher, I.H., Ferreira, M.D., Spósito, M.B., \& Amorim, L. (2009). Citrus postharvest diseases and injuries related to impact on packing lines. Scientia Agricola, 66(2), 210-217

Flood, S.J., Burks, T.F., \& Texeira A.A. (2006). Physical properties of oranges in response to applied gripping forces for robotic harvesting. Transactions of the American Society of Agricultural Engineers, 49(2), 341-346

Fornes, I., Moltó, E., \& Juste, F. (1994). Mechanical harvesting of citrus: evaluation of damage produced and fruit behavior during postharvest. Congreso of the American Society of Agricultural Engineers Milano 1994, report 94-G061

García-Ramos, F.J., Valero, C., Ruiz-Altisent, M. \& Ortiz-Cañavate, J. 2004. Analysis of the mechanical aggressiveness of three orange packing systems: packing table, box filler and net filler. Applied Engineering in Agriculture, 20(6): 827-832

Glancey,JL., \& Kee, WE. (2005). Engineering aspects of production and harvest mechanization for fresh and processed vegetables. HortTechnology, 15(1), 76-79.

Hernández, P. (2000). Caracterización instrumental de "Frutos Electrónicos” y su utilización en la evaluación en las líneas de confección de cítricos. Trabajo final de carrera. Universidad Politécnica de Valencia.

Jobson, J.D. (1991). Applied multivariate data analysis. Volume I: Regression and Experimental Design. New York: Springer-Verlag

Juste, F., Gracia, C., Molto, E., Ibañez, R., \& Castillo, S. (1988). Fruit bearing zones and physical properties of citrus for mechanical harvesting. Proceedings of the Sixth International Citrus Congress: Middle-East, Tel Aviv, Israel, March 6-11, 1801-1809

Kleinbaum, D.G., \& Klein, M. (2002). Logistic regression: a self-learning text. New York: SpringerVerlag

Lu \& Wang. (2007). Dropping bruise fragility and bruise boundary of apple fruit. Transactions of the $A S S A B E, 50(4), 1323-1329$

Menesatti, P., Paglia, G., Solaini, S., Niciarelli, I., \& D’Andrea, S. 2005. Mechanical damage to citrus fruit. Informatore Agrari, 61(2), 53-55

Scherrer Montero, C.R., Loss Schwarz, L., Cunha dos Santos, L., Salete Andreazza, C.,; Pereira Kechinski, C., \& Joao Bender, R. (2009). Postharvest mechanical damage affects fruit quality of 'Montenegrina' and 'Rainha' tangerines. Pesquisa Agropecuaria Brasileira, 44(12), 1636-1640

Ortiz, C., Torregrosa, A., \& Bernad, J.J. (2007).Capacidad de protección frente a daños en la fruta de diferentes superficies de recogida. Congreso Agroingeniería 2007 (Albacete). Libro de actas (ISBN 9788469078945)

Pang, D.W., Studman, C.J., Banks, N.H., \& Baas, P.H. (1996). Rapid assessment of the susceptibility of apples to bruising. Journal of Agricultural Engineering Research, 64(1), 37-47

Timm, E.J., \& Guyer, D.E. (1998). Tart cherry firmness and quality changes during mechanical harvesting and handling. Applied Engineering in Agriculture, 4(2), 153-158. 
Torregrosa, A., Martín, B., Ortiz, C., \& Chaparro, O. (2008). Mechanical harvesting of processed apricots. Applied Engineering in Agriculture, 22(6), 723-729

Torregrosa, A., Gil, J., Ortiz, C., Ortí, E., \& Martín, B. (2009). Mechanical harvesting of oranges and mandarins in Spain. Biosystems Engineering, 104(1), 18-24

Van Canney, T., Tijkens, E., Ramon, H., Verschoe, R., \& Sonck, B. (2003). Characterisation of a potatoshaped instrumented Device. Biosystems Engineering, 86(3), 275-285 